Letter

\title{
Grain boundary precipitation induced by grain crystallographic misorientations in an extruded $\mathrm{Al}-\mathrm{Mg}-\mathrm{Si}-\mathrm{Cu}$ alloy
}

\author{
Wenchao Yang ${ }^{\mathrm{a}, \mathrm{b}, *}$, Shouxun $\mathrm{Ji}^{\mathrm{b}}$, Zhou Li ${ }^{\mathrm{a}}$, Mingpu Wang ${ }^{\mathrm{a}}$ \\ a School of Materials Science and Engineering, Central South University, Changsha 410083, China \\ ${ }^{\mathrm{b}}$ Brunel Centre for Advanced Solidification Technology (BCAST), Brunel University London, Uxbridge UB8 3PH, UK
}

\begin{abstract}
A B S T R A C T
The grain boundary precipitation induced by grain crystallographic misorientations in an extruded $\mathrm{Al}-\mathrm{Mg}-\mathrm{Si}-\mathrm{Cu}$ alloy was investigated by electron back-scattering patterns and high resolution transmission electron microscopy. The results showed that compared with the recrystallization cube $\{100\}\langle 001\rangle$ texture, the deformation brass $\{110\}\langle 112\rangle$ texture prevailed in the microstructure. The brass texture mainly contributed for the formation of low angle grain boundaries, where the pre- $\beta^{\prime \prime} / \beta^{\prime}$ phases were formed during precipitation. The recrystallization cube texture predominately induced the formation of high angle grain boundaries, where the $Q^{\prime} / Q$ phases related to the corrosion were precipitated. And, high and low grain boundary was $23.5 \%$ and $76.5 \%$ proportion in the microstructure, respectively. Finally, it was believed that in order to improve the resistance to intergranular corrosion of alloy, the recrystallization cube $\{100\}\langle 001\rangle$ texture should be inhibited as far as possible.
\end{abstract}

\section{Introduction}

Owing to favourable strength-to-weight ratio, medium strength and good corrosion resistance, $\mathrm{Al}-\mathrm{Mg}-\mathrm{Si}$ alloys are widely used as extruded profiles in rail transportation and automotive industry [1-3]. Addition of copper into Al-Mg-Si wrought alloys is an effective approach to improve their mechanical properties through the precipitation of $\mathrm{Q}^{\prime}$ phase [4,5]. Unfortunately, copper is found to increase the susceptibility to intergranular corrosion of aluminium alloys [6], which is significantly associated with the microstructure [7]. Recent research had confirmed that the nano-scale continuous $\mathrm{Cu}$-rich films existed at grain boundaries were capable of acting as corrosion channels in $\mathrm{Al}-\mathrm{Mg}-\mathrm{Si}-\mathrm{Cu}$ alloys [6]. The $\mathrm{Cu}$-rich films finally transformed into Cu-rich $\mathrm{Q}^{\prime} / \mathrm{Q}$ phases. Therefore, the control of $\mathrm{Q}^{\prime} / \mathrm{Q}$ precipitation is critical to improve the corrosion resistance in $\mathrm{Al}-\mathrm{Mg}-\mathrm{Si}-\mathrm{Cu}$ alloys. A heat treatment process, such as T6I6 [8], had been found to be able to reduce the intergranular corrosion of $\mathrm{Al}-\mathrm{Mg}-\mathrm{Si}-\mathrm{Cu}$ alloys by controlling the precipitation of $\mathrm{Q}^{\prime} / \mathrm{Q}$ phases at grain boundaries. Therefore, the grain boundary precipitation is closely associated with the corrosion behaviour in $\mathrm{Al}-\mathrm{Mg}-\mathrm{Si}-\mathrm{Cu}$ alloys.
The received $\mathrm{Al}-\mathrm{Mg}-\mathrm{Si}-\mathrm{Cu}$ alloys are processed into sheets by the hot extrusion. During thermo-mechanical processing, new grain boundaries are produced in the microstructure with the formation of textures. It is therefore important to understand more about the precipitation in association with the grain boundaries. This is also particularly useful for understanding the mechanism of intergranular corrosion because the corrosion channels are always along high angle grain boundaries [9]. Therefore, in the present work, we attempted to investigate the interaction among the textures, grain boundaries and precipitates in an extruded $\mathrm{Al}-\mathrm{Mg}-\mathrm{Si}-\mathrm{Cu}$ alloy. Based on the texture characterisation, the precipitation at high and low angle grain boundaries was analysed. The interaction between the textures and precipitation at grain boundaries was discussed with the intergranular corrosion.

\section{Experimental}

The Al-0.65 wt.\%Mg-0.73 wt.\%Si-0.13 wt.\%Cu alloy was received in the form of as-extruded sheets with a cross section of $15 \mathrm{~cm}$ wide and $5 \mathrm{~mm}$ thick. Prior to the heat treatment, the as-extruded sheets were cut into small samples with $5 \times 20 \times 20 \mathrm{~mm}$ in size. The sample was heated up to $550^{\circ} \mathrm{C}$ and maintained at the temperature for $1 \mathrm{~h}$ to achieve a complete solution, followed by an immediate water quenching to room temperature $\left(\sim 20^{\circ} \mathrm{C}\right)$. The ageing treatment was performed at $175^{\circ} \mathrm{C}$ to investigate the grain boundary precipitation. The samples for electron back-scattering patterns (EBSD) and transmission electron microscope (TEM) analysis were prepared by electrolytic polishing with nitric acid and methyl alcohol $(1: 4)$ at $22 \mathrm{~V}$ with a temperature between -20 and $-30^{\circ} \mathrm{C}$. The EBSD measurements were carried out on the RD-ND plane using FEI Sirion200 FEG scanning 
electron microscope operated at $15 \mathrm{kV}$ and the statistic orientation analysis were carried out using OIM TSL software. JEOL-2100F high resolution transmission electron microscope (HRTEM) was used for TEM observation.

\section{Results and discussion}

Fig. 1 showed the EBSD analysis results of the experimental alloy. In Fig. 1a, the EBSD orientation mapping confirmed that the microstructure consisted of coarse deformed grains and fine recrystallized grains. The fine recrystallized grains were mainly located between coarse deformed grains. Furthermore, the corresponding $\langle 001\rangle,\langle 011\rangle$ and $\langle 111\rangle$ pole figures were presented in Fig. $1 \mathrm{~b}$ by calculating the EBSD orientation mapping. It was seen that there were two main textures in the microstructure: brass $\{110\}\langle 112\rangle$ texture and recrystallization cube $\{100\}\langle 001\rangle$ texture. Fig. 1c presented the corresponding distribution map of the high and low angle grain boundaries. It revealed that these coarse deformed grains actually contained lots of sub-grains, therefore, the low angle grain boundaries $\left(<15^{\circ}\right)$ existed within the coarse deformed grains, while the high angle grain boundaries $\left(>15^{\circ}\right)$ were mainly distributed between the deformed grains and the recrystallized grains. Moreover, the proportion of misorientation angles in the microstructure was displayed in Fig. 1d. It clearly showed that the low angle grain boundaries induced mainly by the deformed grains were predominant in the microstructure with
76.5\% proportion and the high angle grain boundaries induced mainly by the recrystallized grains were only $23.5 \%$ proportion.

Generally, the microstructure features are closely associated with the extrusion process including a plastic deformation and a heat treatment process. During the plastic deformation, the multiple slip systems $\{111\}\langle 110\rangle$ in FCC Al matrix were simultaneously activated. The interaction resulted in the tensile axis parallel to $\langle 112\rangle$ direction and the compression axis parallel to the normal direction of $\{110\}$ plane. Consequently, some grains were prone to produce the brass $\{110\}\langle 112\rangle$ texture. In the meantime, the alloy also underwent a heat treatment process. A large number of dislocations formed during the deformation began to climb and cross-slip to produce the recovery and recrystallization process, which might result in the formation of $\{100\}\langle 001\rangle$ texture.

In order to find out the evolution process of precipitation at different types of grain boundaries, the artificial ageing was carried out for the experimental alloy. The misorientation between grains was determined by electron diffraction and precipitates were confirmed by diffraction features and lattice parameters. At the early stage of ageing at $175^{\circ} \mathrm{C}$ for $30 \mathrm{~min}$, the grain boundary precipitations were presented in Fig. 2. It was found that the spheroidal GP zones had been precipitated with a size of 2-4 $\mathrm{nm}$ in the Al matrix as shown by the arrow. Fig. 2a presented two grains with different orientations. It was clear that the grain A was on the $[001]_{\mathrm{Al}}$ axis zone and the grain $\mathrm{B}$ was away from the $[001]_{\mathrm{Al}}$ axis zone based
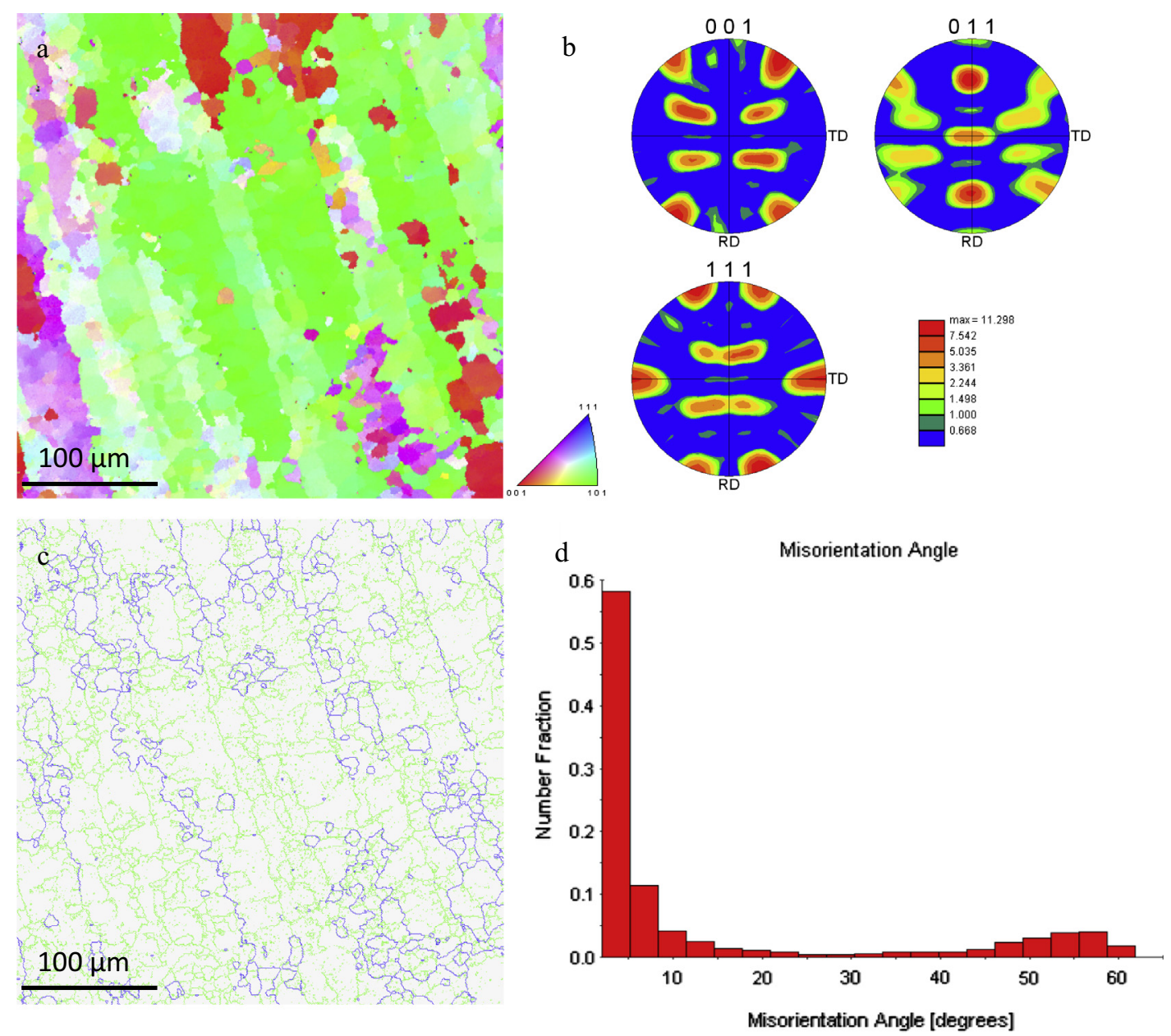

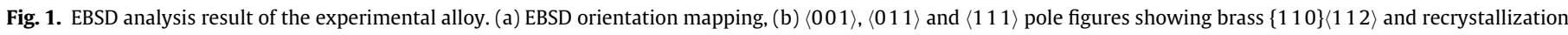

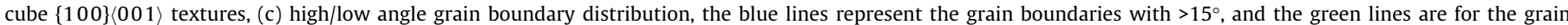

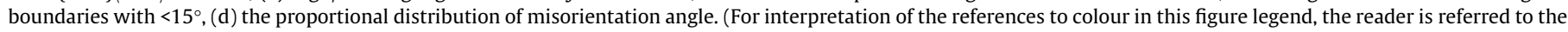
web version of this article.) 

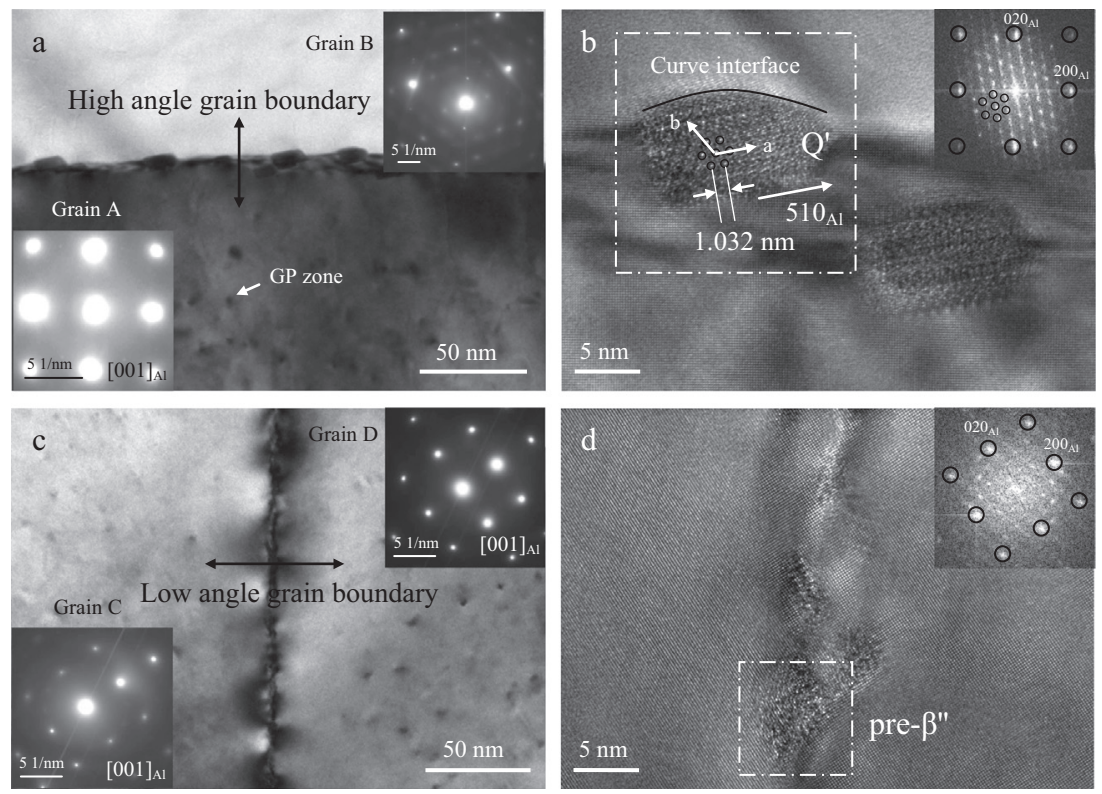

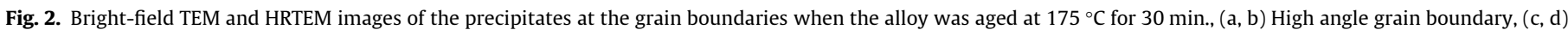

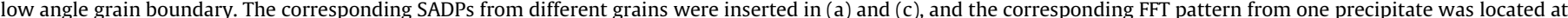
the upper right corner in (b) and (d), respectively.

on the corresponding selected area electron diffraction (SADP) observation inserted at the lower left and upper right corners, respectively. This confirmed that there was a high angle grain boundary between grains $\mathrm{A}$ and $\mathrm{B}$, where the precipitates were $7 \times 13 \mathrm{~nm}$ and exhibited a rectangle-shaped morphology on the cross-section. HRTEM image from the precipitates was shown in Fig. 2b. The corresponding fast Fourier filtering transform (FFT) pattern from one precipitate was inserted at the right upper corner. It was observed that this precipitate showed hexagonal lattice streaks with $1.032 \mathrm{~nm}$ lattice parameter and typical diffraction spots in FFT pattern, and its cross-section lay along the $[510]_{\mathrm{Al}}$ direction, which were essentially consistent with the orientation and structure of $\mathbf{Q}^{\prime}$ phase in Al-Mg-Si-Cu alloys [10]. Based on the HRTEM image, the orientation relationships between $\mathrm{Q}^{\prime}$ phase and $\mathrm{Al}$ matrix was

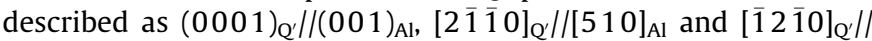
$\left[\begin{array}{ll}1 & 10\end{array}\right]_{\mathrm{Al}}$, which was belonged to the variant 2 in 12 variants of $\mathrm{Q}^{\prime}$ phases [10]. Moreover, it was noticed that this $\mathbf{Q}^{\prime}$ precipitate across the high angle grain boundary exhibited a faceted interface with the grain $\mathrm{A}$ and a curve interface with the grain $\mathrm{B}$.

Under the same ageing condition, the precipitates at low angle grain boundary were displayed in Fig. $2 \mathrm{c}$ and d. Adjacent to the grain boundary in Fig. 2c, several spheroidal GP zones were detected. However, the precipitates along the low angle grain boundary were completely different from that along the high angle grain boundary in terms of size and morphology. The precipitates were fine with $2-5 \mathrm{~nm}$ in size and these grain boundary precipitates presented a higher number density than that along the high angle grain boundary in Fig. 2a. HRTEM image of these precipitates was presented in Fig. 2d, where the corresponding FFT pattern from one precipitate was inserted at the upper right corner. It was found that, in addition to the diffraction patterns from the Al matrix, some weak diffraction spots were also detected in the FFT pattern, which was similar to that from $\beta^{\prime \prime}$ phase [11]. However, no clear periodic lattice streaks could be observed in the HRTEM image, which indicated that this precipitate might not be the $\beta^{\prime \prime}$ phase. It was anticipated to be a transition phase between GP zone and $\beta^{\prime \prime}$ phase, named as pre- $\beta^{\prime \prime}$ phase, implying that these precipitates at the low angle grain boundary just contained $\mathrm{Al}, \mathrm{Mg}$ and $\mathrm{Si}$ atoms [12].
Fig. 3 showed the precipitates at the grain boundaries of alloy under over-aged stage at $175^{\circ} \mathrm{C}$ for $36 \mathrm{~h}$. Obviously, the needleshaped $\beta^{\prime \prime}$ phases were precipitated in the grains, which presented some typical "cross-shaped" diffraction streaks in the [001 $]_{\mathrm{Al}}$ SADP [8]. Fig. 3a presented a high angle grain boundary (the inserts were the corresponding SADPs from the grains $\mathrm{E}$ and $\mathrm{F}$, respectively). It was observed the existence of coarse precipitates with a size of $15 \times 40 \mathrm{~nm}$ at the grain boundary. The HRTEM image from one precipitate at the high grain boundary and the corresponding FFT pattern were shown in Fig. $3 \mathrm{~b}$. Different from that in Fig. $2 \mathrm{~b}$, the precipitates lay on $(001)_{\mathrm{Al}}$ plane and its long axis was parallel to the $\left[\begin{array}{lll}0 & 10\end{array}\right]_{\mathrm{Al}}$ direction. Meanwhile, it was found that the typical diffraction spots around $1 / 2220_{\mathrm{Al}}$ position in the corresponding FFT pattern could be observed under the $[001]_{\mathrm{Al}}$ zone axis. According to the diffraction features, these precipitates should be the $\mathrm{Q}^{\prime}$ phase, belonged to the variant 5 in 12 variants $Q^{\prime}$ phases, and the diffraction spots were actually formed by the double diffraction effect between $\mathrm{Q}^{\prime}$ phase and $\mathrm{Al}$ matrix [10]. The $\mathrm{Q}^{\prime}$ precipitates at the high angle grain boundaries would eventually transform into the equilibrium $Q$ phases with prolonged precipitation. The precipitates formed at the low angle grain boundaries were further shown in Fig. $3 c$ and $d$ where the misorientation between grains $\mathrm{G}$ and $\mathrm{H}$ was only $0.53^{\circ}$ based on the diffraction analysis. It was obvious that the precipitates had a $\{310\}_{\mathrm{Al}}$ habit plane and exhibited a hexagonal lattice streaks with $0.715 \mathrm{~nm}$ lattice parameter. The diffraction spots in the FFT patterns further confirmed that the precipitates should be the $\beta^{\prime}$ phases [10]. Therefore, the orientation relationships could be described as $(0001)_{\beta^{\prime}} / /(001)_{\mathrm{Al}}$,

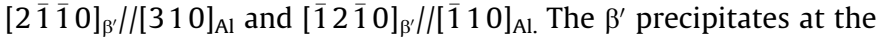
low angle grain boundaries would eventually transform into the equilibrium $\beta-\mathrm{Mg}_{2} \mathrm{Si}$ phases.

Actually, the diffusion of atoms at grain boundary was quite complex, and it was always effected by other factors, such as grain boundary misorientation. If the misorientation between two grains was smaller, the atom arrangement at the grain boundary was quite regular, and the corresponding defects are less. Therefore, the diffusion of atoms at the grain boundary has no obvious difference compared with the grains, such as, a low angle grain boundary. However, when the misorientation was bigger, the atom 

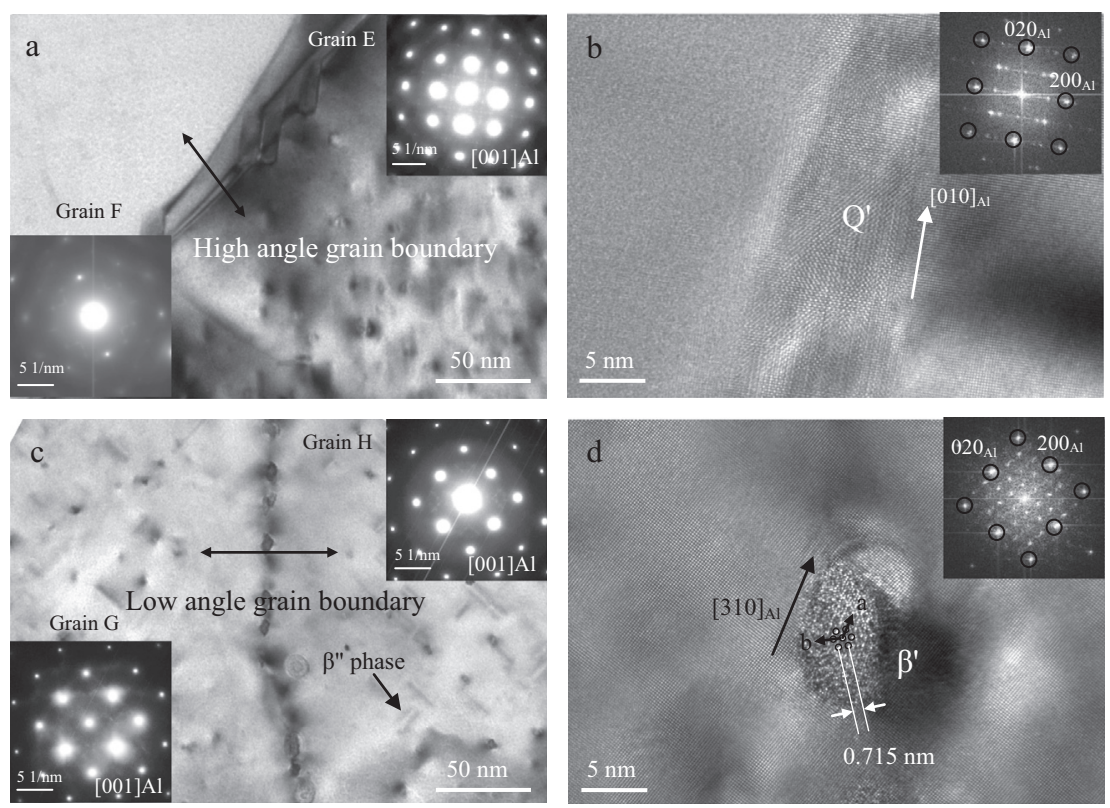

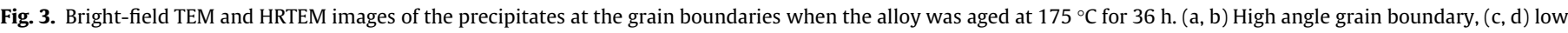

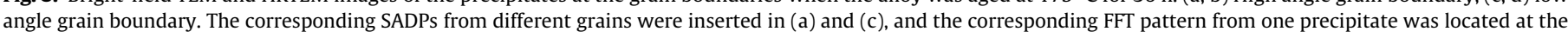
upper right corner in (b) and (d), respectively.

arrangement at the grain boundary was not regular so that the diffusion of atoms would be quicker, such as a high grain boundary. Therefore, the diffusion of atoms at the high angle boundary was obviously quicker than that at the low angle boundary. As a result, $\mathrm{Mg}, \mathrm{Si}$ and $\mathrm{Cu}$ atom were prone to segregate towards the high angle grain boundaries to form the $\mathrm{Q}^{\prime}$ phase during precipitation at the same ageing condition. Conversely, there is less or no segregation towards the low angle grain boundaries in $\mathrm{Al}-\mathrm{Mg}-\mathrm{Si}-\mathrm{Cu}$ alloys [13].

The experimental observations confirmed that the grain boundary precipitates were different with the structure of boundaries. At the high angle grain boundaries, the precipitation sequence followed $\mathrm{Q}^{\prime} \rightarrow \mathrm{Q}$. At the low angle grain boundaries, the precipitation sequence followed pre- $\beta^{\prime \prime} \rightarrow \beta^{\prime} \rightarrow \beta$. Because $Q^{\prime} / Q$ phase containing $\mathrm{Cu}$ atoms had been confirmed to be detrimental for the intergranular corrosion resistant [6], the high angle grain boundaries were more susceptive to the corrosion due to the preference of forming $\mathrm{Q}^{\prime} / \mathrm{Q}$ precipitates. Based on EBSD analysis results, these high angle grain boundaries were predominantly contributed by grains with the recrystallized cube $\{100\}\langle 001\rangle$ texture. Therefore, the recrystallization cube $\{100\}\langle 001\rangle$ texture should be inhibited as far as possible in order to improve the resistance to intergranular corrosion in the extruded $\mathrm{Al}-\mathrm{Mg}-\mathrm{Si}-\mathrm{Cu}$ alloys. In other words, the low angle grain boundaries were beneficial for the intergranular corrosion resistance. Therefore, a suitable extrusion and quenching process was critical for the corrosion performance in $\mathrm{Al}-\mathrm{Mg}-\mathrm{Si}-\mathrm{Cu}$ alloys.

\section{Conclusion}

The texture formed during thermal mechanical processing was closely associated with the precipitation at grain boundaries. Compared with the recrystallization cube $\{100\}\langle 001\rangle$ texture, the deformation brass $\{110\}\langle 112\rangle$ texture prevailed in the microstructure of the extruded $\mathrm{Al}-\mathrm{Mg}-\mathrm{Si}-\mathrm{Cu}$ alloy. The brass $\{110\}\langle 112\rangle$ texture was capable of introducing most low angle boundaries, where the precipitation sequence followed the transformation of pre- $\beta^{\prime \prime} \rightarrow \beta^{\prime} \rightarrow \beta$. However, the recrystallization cube $\{100\}\langle 001\rangle$ texture was mainly resulted in the formation of high angle boundaries, where the precipitation sequence followed $\mathrm{Q}^{\prime} \rightarrow \mathrm{Q}$. Because the precipitation of $\mathrm{Q}^{\prime} / \mathrm{Q}$ phase at high angle grain boundaries were mainly responsible for intergranular corrosion, it was thus essential to inhibit the recrystallization texture in order to improve the corrosion resistance of the extruded $\mathrm{Al}-\mathrm{Mg}-\mathrm{Si}-\mathrm{Cu}$ alloys.

\section{Acknowledgments}

It is gratefully acknowledged for the financial support from Hunan Provincial Innovation Foundation for Postgraduate (CX2010B044), P.R. China. And the authors would like to thanks to Dr. Y. Huang at BCAST, Brunel University London, UK for his helpful and inspiring discussion.

\section{References}

[1] C.D. Marioara, S.J. Andersen, J. Jansen, H.W. Zandbergen, Acta Mater. 51 (2003) 789-796.

[2] Y. Meng, J. Cui, Z. Zhao, Y. Zuo, J. Alloys Comp. 573 (2013) 102-111.

[3] F.J.H. Ehlers, S. Dumoulin, J. Alloys Comp. 591 (2014) 329-336.

[4] D.L. Chakrabarti, D.E. Laughlin, Prog. Mater. Sci. 49 (2004) 389-410.

[5] H.S. Hasting, J.C. Walmsley, A.T.J. Van Helvoort, C.D. Marioara, S.J. Andersen, R. Holmestad, Phil. Mag. Lett. 86 (2006) 589-597.

[6] G. Svenningsen, M.H. Larsen, J.C. Walmsley, J.H. Nordlien, K. Nisancioglu, Corros. Sci. 48 (2006) 1528-1543.

[7] J. Holmestad, M. Ervik, C.D. Marioara, J.C. Walmsley, Mater. Sci. Forum. 794 796 (2014) 951-956.

[8] X.F. Sheng, W.C. Yang, C.D. Xia, J. Gong, M.P. Wang, Z. Li, Q. Zhang, Chin. J. Nonferr. Met. 22 (2012) 1276-1282.

[9] T. Minoda, H. Yoshida, Metall. Mater. Trans. A 33 (2002) 2891-2898.

[10] W.C. Yang, M.P. Wang, X.F. Sheng, Q. Zhang, L.P. Huang, Phil. Mag. Lett. 91 (2011) 150-160.

[11] W.C. Yang, M.P. Wang, R.R. Zhang, Q. Zhang, X.F. Sheng, Scripta Mater. 62 (2010) 705-708.

[12] J.H. Chen, E. Costan, M.A. van Huis, Q. Xu, H.W. Zandbergen, Sicence 312 (2006) 416-419.

[13] M. De Hass, J.T.M. De Hosson, Scripta Mater. 44 (2001) 281-286. 